\title{
PENGEMBANGAN MEDIA PEMBELAJARAN E-LEARNING MENGGUNAKAN MOODLE BERBASIS E-MODUL PADA PEMBELAJARAN INTALASI PENERANGAN LISTRIK UNTUK KELAS XI TITL SMK SWASTA IMELDA MEDAN
}

\author{
Feber Dhika Purba ${ }^{1}$, Hamonangan Tambunan ${ }^{2}$ \\ Fakultas Teknik, Universitas Negeri Medan \\ 1eberdhika11@gmail.com, ${ }^{2}$ hamtambun@gmail.com
}

\begin{abstract}
This study aims to know the feasibility of media, as well as to know the response to the development of e-learning media using moodle-based e-modules on the learning of electrical lighting installations at SMKS Imelda Medan. This e-learning development uses addie development model adapted from Mollenda and Reiser (2003). namely: (1) analysis, (2) design, (3) development, (4) implementation, and (5) evaluation. E-learning feasibility assessment is conducted by material experts, media experts, and teachers as respondents. Data collection techniques used are questionnaire techniques to obtain quantitative data as primary data and qualitative data in the form of suggestions or comments as data for e-learning improvements. Quantitative data obtained is then converted into qualitative data using ideal assessment criteria. The results showed that: e-learning has "feasible" criteria from material experts with an average assessment of 4.00, from e-learning media experts have "feasible" criteria with an average rating of 4.13; e-learning trial results to respondents showed that e-learning has a "high acceptance" criteria with an average rating of 4.05. Based on the results of the development research obtained, it can be concluded that the development of e-learning using moodle-based e-modules in SMKS Imelda Medan is feasible to be developed.
\end{abstract}

\section{Key Words: E-Learning Moodle, learning media, E-module}

\begin{abstract}
Abstrak
Penelitian ini bertujuan untuk mengetahui kelayakan media, serta mengetahui respon terhadap pengembangan media e-learning menggunakan moodle berbasis $e$-modul pada pembelajaran instalasi penerangan listrik di SMKS Imelda Medan. Pengembangan e-learning ini menggunakan model pengembangan ADDIE diadaptasi dari Mollenda dan Reiser (2003). yakni: (1) analisis, (2) desain, (3) pengembangan, (4) implementasi, dan (5) evaluasi. Penilaian kelayakan e-learning dilakukan oleh ahli materi, ahli media, dan guru sebagai responden. Teknik pengumpulan data yang digunakan adalah teknik angket untuk memperoleh data kuantitatif sebagai data primer dan data kualitatif berupa saran atau komentar sebagai data untuk perbaikan e-learning. Data kuantitatif yang diperoleh kemudian dikonversi menjadi data kualitatif menggunakan kriteria penilaian ideal. Hasil penelitian menunjukkan bahwa: $e$ learning memiliki kriteria "layak" dari ahli materi dengan rerata penilaian 4.00, dari ahli media $e$ learning memiliki kriteria "layak" dengan rerata penilaian 4.13; hasil uji coba e-learning kepada responden menunjukkan bahwa e-learning memiliki kriteria "akseptansi tinggi" dengan rerata penilaian 4.05. Berdasarkan hasil dari penelitian pengembangan yang diperoleh maka dapat disimpulkan bahwa pengembangan e-learning menggunakan moodle berbasis e-modul di SMKS Imelda Medan layak untuk dikembangkan.
\end{abstract}

Kata Kunci: E-Learning Moodle, Media Pembelajaran, E-Modul

\section{PENDAHULUAN}

Pendidikan yang ikut berperan dalam mewujudkan cita-cita negara untuk meningkatkan sumber daya manusia yang berkualitas dan terampil adalah Sekolah Menengah Kejuruan (SMK), yaitu salah satu jenjang pendidikan menengah dengan kekhususan mempersiapkan lulusannya untuk siap bekerja. Pendidikan kejuruan adalah bagian dari sistem pendidikan yang mempersiapkan seseorang agar lebih mampu bekerja pada suatu kelompok pekerjaan atau satu bidang pekerjaan dari pada bidang-bidang pekerjaan lainnya (Rupert Evans, 1978). Bidang studi yang diajarkan secara mendalam dimaksudkan untuk menjadi bekal dalam memasuki dunia kerja. Hal itu sejalan dengan Undang-Undang Sistem 
Pendidikan Nasional No. 20 Tahun 2003 pasal 3 mengenai tujuan pendidikan nasional dan penjelasan pasal 15 yang menyebutkan bahwa pendidikan kejuruan merupakan pendidikan menengah yang mempersiapkan peserta didik terutama untuk bekerja di bidang tertentu. Dengan tujuan tersebut, maka jelas SMK membekali pada siswanya dengan keahlian tertentu agar siap di tempatkan dalam dunia kerja sesuai kemampuan yang telah didapatkan.

Namun berdasarkan data Badan Pusat Statistik (BPS) provinsi Sumatera Utara pada Agustus 2019, Tingkat Pengangguran Terbuka (TPT) untuk Sekolah Menengah Kejuruan adalah paling tinggi diantara tingkat pendidikan lain yaitu sebesar 8,50 persen begitu juga dengan kondisi Agustus 2018. TPT tertinggi berikutnya terdapat SMA sebesar 7,54 persen. Dengan kata lain, ada penawaran tenaga kerja yang berlebih terutama pada tingkat pendidikan SMK dan SMA. Sedangkan mereka yang berpendidikan rendah cenderung mau menerima pekerjaan apa saja, dapat dilihat dari TPT SD ke bawah paling kecil diantara semua tingkat pendidikan yaitu sebesar 2,52 persen seperti grafik pada gambar 1 .

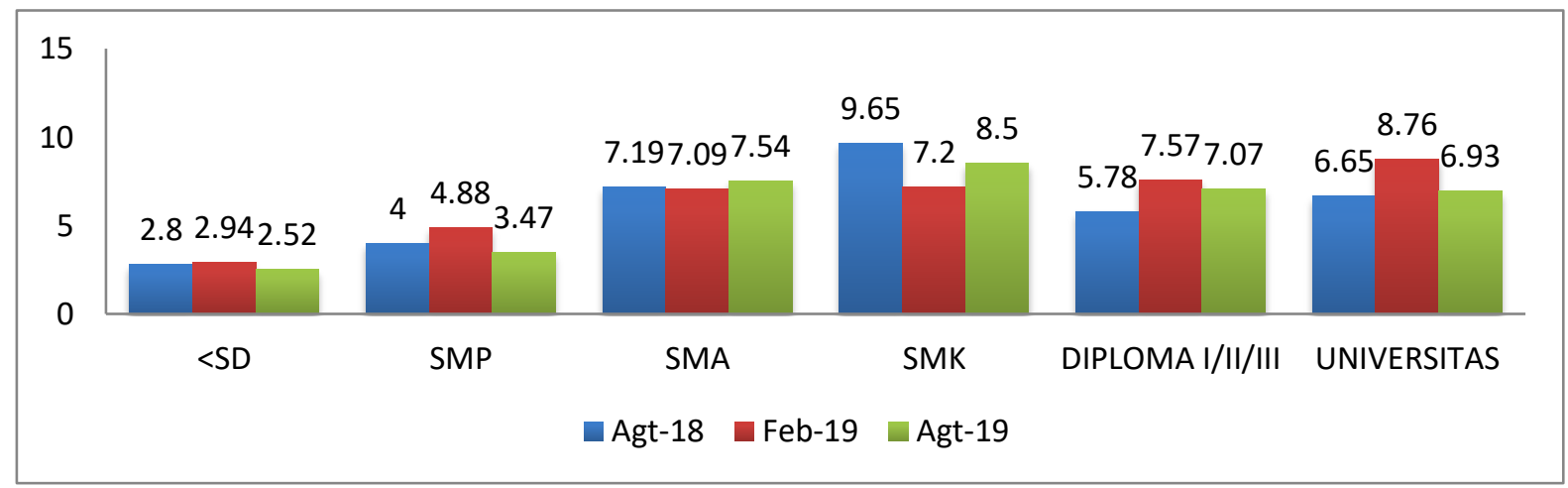

Gambar 1 Perkembangan Pengangguran Terbuka (TPT) Menurut Tingkat Pendidikan Tertinggi yang Ditamatkan 2018-2019

Data yang disajikan oleh Badan Pusat Statistik tentang keadaan pengangguran lulusan SMK memberikan gambaran masih diperlukan upaya upaya untuk meningkatkan mutu lulusan SMK. Pada kesempatan ini yang menjadi sorotan adalah media pembelajaran. Media pembelajaran dapat dipahami sebagai segala sesuatu yang dapat menyampaikan atau menyalurkan pesan dari suatu sumber secara terencana, sehingga terjadi lingkungan belajar yang kondusif dimana penerimanya dapat melakukan proses belajar mengajar secara efisien dan efektif. Sehingga materi pembelajaran lebih cepat diterima siswa dengan utuh serta menarik minat siswa untuk belajar lebih lanjut (Rayandra Asyar, 2011: 8).

Sistem E-learning menawarkan ruang informasi yang mengundang aktif kolaborasi. E-learning mewakili ide-ide inovatif dibidang pembelajaran, menyediakan akses cepat kepengetahuan dan informasi spesifik (Sheshasaayee \& Bee, 2017). Pembelajaran itu disusun dengan menggunakan media internet untuk dapat mendukung proses pembelajaran (Michael, 2013:27). Maka dengan itu e-learning digunakan sebagai pendukung proses belajar mengajar yang dilaksanakan tanpa harus bertatap muka secara langsung antara pendidik dengan siswa/i (Ardiansyah, 2013).

Beberapa peneliti terdahulu melaporkan bahwa siswa yang mengikuti proses pembelajaran yang menggunakan e-learning memberikan dampak positif terhadap hasil belajar (James Marshall, 2004; Abuhassna \& Yahaya, 2018; Nadire Cavus, 2015; Soree Yengyuno, 2017). E-learning mempermudah interaksi antara peserta didik dengan bahan/materi pelajaran. Sesuai dengan kebutuhan, guru dapat pula memberikan kesempatan kepada peserta didik untuk mengakses bahan belajar tertentu maupun soalsoal ujian yang hanya dapat diakses oleh peserta didik sekali saja dan dalam rentangan waktu tertentu pula (Website Kudos, 2002). Berdasarkan itu maka akan dikembangkan media pembelajaran e-learning menggunakan Moodle berbasis e-modul yang diharapkan bisa menumbuhkan minat belajar siswa demi tercapainya pembelajaran yang efektif dan efisien.

\section{METODE}

Penelitian ini akan dilaksanakan di SMK Swasta Imelda Medan yang beralamat di Jalan Bilal No.52 Pulo Brayan Darat 1 Medan Timur. Penelitian ini dilaksanakan pada semester ganjil TA 2020/2021. Sasaran produk yang dihasilkan dalam penelitian ini adalah siswa kelas XI TITL SMK Swasta Imelda Medan. 
Adapun jenis dari penelitian ini adalah research and development $(R \& D)$. Research and Development $(R \& D)$ adalah metode penelitian yang digunakan untuk menghasilkan produk tertentu, dan menguji keefektifan produk tersebut. Produk yang dihasilkan dalam penelitian ini berupa media pembelajaran e-learning menggunakan moodle berbasis e-modul. Pengembangan media menggunakan model pengembangan ADDIE (Analysis-Design-Develop-Implement-Evaluate). Model ini dikembangkan oleh Mollenda dan Reiser (2003). Model ini menggunakan 5 tahap pengembangan yakni: Penelitian dan pengembangan ini menggunakan pengumpulan data menggunakan angket. Angket merupakan kumpulan pertanyaan-pertanyaan yang tertulis yang digunakan untuk memperoleh informasi dari responden tentang diri pribadi atau hal-hal yang ia ketahui. Instrumen yang dipakai dalam penelitian ini diadaptasi dari Instrumen Penilaian Multimedia Pembelajaran (Sriadhi, 2019).

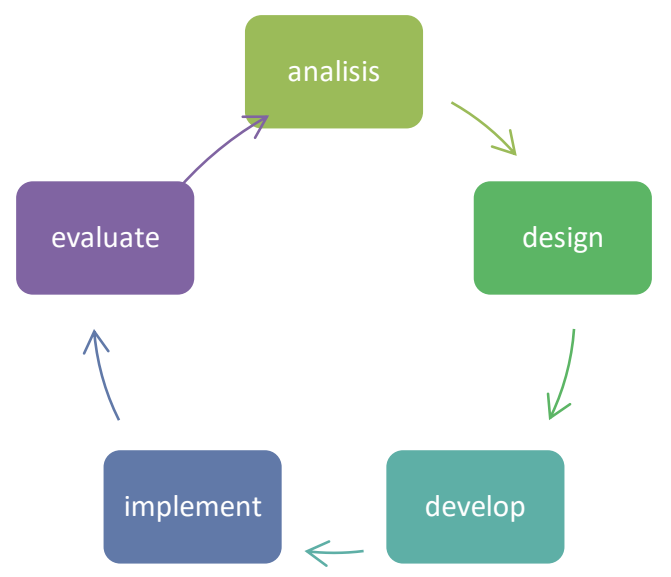

Gambar 2. Model Pengembangan ADDIE

Penelitian ini menggunakan tiga instrumen yaitu instrumen validasi ahli materi, intrumen validasi ahli media, dan instrumen uji coba untuk responden di SMK. Teknik analisis data yang digunakan dalam penelitian meliputi analisis data secara kualitatif dan kuantitatif. Tahap awal penelitian pengembangan dilakukan dengan pengumpulan referensi mengenai media pembelajaran e-learning, tahap selanjutnya yaitu penyusunan instrumen penelitian dan pengembangan media. Tahap terakhir adalah penilaian. Media ini divalidasi oleh ahli materi dan ahli media. Setelah divalidasi oleh ahli materi dan ahli media, media kemudian direvisi sehingga diperoleh media revisi tahap I. Media hasil revisi tahap I kemudian diujicobakan dalam pembelajaran di kelas. Media yang telah melalui proses ujicoba akan direvisi kembali. Berdasarkan tahap-tahap tersebut, maka akan dihasilkan produk akhir media pembelajaran yang efektif.

\section{HASIL DAN PEMBAHASAN}

Setelah proses pembuatan desain produk media pembelajaran e-learning menggunakan moodle berbasis e-modul, selanjutnya peneliti akan melakukan tahapan. Tahap yang dilakukan dalam pengembangan ini antara lain yaitu validasi ke ahli media, validasi ke ahli materi, dan respon dari responden.

Validator ahli materi menilai e-learning dari 2 aspek yaitu konten/materi multimedia dan kebahasaan. Kriteria penilaian dengan 5 kategori yaitu sangat baik, baik, kurang baik, tidak baik, sangat tidak baik. Data hasil penelitian yang diberikan oleh ahli materi dapat dilihat pada tabel berikut

Tabel 1 Validasi Ahli Materi

\begin{tabular}{|c|c|c|c|c|c|c|}
\hline No. & \multicolumn{2}{|c|}{ Aspek media } & Konten dan & kebahasaan & Total & Mean skor dan \\
\hline \multirow[t]{2}{*}{1} & \multirow[t]{2}{*}{ Penilai } & Thh skor & 63 & 29 & 92 & \multirow{2}{*}{$\begin{array}{c}4,00 \\
\text { (Layak) }\end{array}$} \\
\hline & & Jhitem & 16 & 7 & 23 & \\
\hline 2 & \multicolumn{2}{|c|}{ Total skor } & 63 & 29 & \multicolumn{2}{|r|}{92} \\
\hline 3 & \multicolumn{2}{|c|}{ Mean skor } & 3,93 & 4,14 & \multicolumn{2}{|r|}{4,00} \\
\hline 4 & \multicolumn{2}{|c|}{ Hasil penilaian } & Layak & Layak & \multicolumn{2}{|r|}{ Layak } \\
\hline
\end{tabular}


Berdasarkan penilaian ahli materi, kelayakan e-learning mencapai nilai rata-rata 4,00. Hal ini dapat diartikan bahwa ahli materi menyatakan e-learning pada pemateri instalasi penerangan listrik dalam kategori layak digunakan sebagai bahan pembelajaran.

Validator ahli media menilai e-learning dari 3 aspek yaitu tampilan, interaktivitas, kemanfaatan. Kriteria penilaian dengan 5 kategori yaitu sangat baik, baik, kurang baik, tidak baik, sangat tidak baik. Data hasil penelitian yang diberikan oleh ahli media dapat dilihat pada tabel berikut

Tabel 2 Validasi Ahli Media

\begin{tabular}{|c|c|c|c|c|c|c|c|}
\hline No & \multicolumn{2}{|c|}{ Aspek media } & $\begin{array}{c}\text { Tampila } \\
\text { n }\end{array}$ & Interaktivitas & kemanfaatan & Total & $\begin{array}{c}\text { Mean skor } \\
\text { dan } \\
\text { penilaian }\end{array}$ \\
\hline \multirow{2}{*}{1} & \multirow{2}{*}{\begin{tabular}{c} 
Penilai \\
\cline { 2 - 7 }
\end{tabular}} & Jlh skor & 50 & 21 & 20 & 91 & $\begin{array}{c}4,13 \\
\text { (Layak) }\end{array}$ \\
\hline 2 & \multicolumn{2}{|c|}{ Total skor } & 50 & 21 & 20 & 91 \\
\hline 3 & \multicolumn{2}{|c|}{ Mean skor } & 4,16 & 4,20 & 4,00 & 4,13 \\
\hline 4 & Hasil penilaian & Layak & Layak & Layak & Layak \\
\hline
\end{tabular}

Berdasarkan penilaian ahli media, kelayakan $e$-learning mencapai nilai rata-rata 4,13. Hal ini dapat diartikan bahwa ahli media menyatakan e-learning menggunakan moodle berbasis e-modul pada media instalasi penerangan listrik dalam kategori layak digunakan sebagai bahan pembelajaran.

Subjek uji coba yaitu guru kelas XI di SMKS IMELDA MEDAN. Guru sebagai responden memberikan respon penilaian berdasarkan aspek materi multimedia, evaluasi, desain dan fasilitas media, dan efek pedagogi. Data hasil penilaian yang diberikan oleh responden (Guru) dapat dilihat pada Tabel di bawah ini

Tabel 3 Validasi responden (guru)

\begin{tabular}{|c|c|c|c|c|c|c|c|c|}
\hline & \multicolumn{2}{|c|}{ Aspek Media } & \multirow{2}{*}{$\begin{array}{c}\text { Materi } \\
29\end{array}$} & \multirow{2}{*}{$\begin{array}{c}\text { Evaluasi } \\
12\end{array}$} & \multirow{3}{*}{$\begin{array}{c}\text { Desain } \\
25 \\
\end{array}$} & \multirow{3}{*}{$\begin{array}{c}\text { Pedagogi } \\
16\end{array}$} & \multirow{2}{*}{$\begin{array}{c}\text { Total } \\
82 \\
\end{array}$} & \multirow{2}{*}{$\begin{array}{c}\text { Mean skot } \\
\text { dan } \\
\text { akseptans }\end{array}$} \\
\hline \multirow{3}{*}{1} & Resnonden & Th skor & & & & & & \\
\hline & Nesponcent & TIII DR & 27 & & & & & \multirow{2}{*}{4,10} \\
\hline & & Jin item & 7 & 3 & 6 & 4 & 20 & \\
\hline \multirow[t]{2}{*}{2} & Responden & Jlh skor & 28 & 12 & 24 & 16 & 80 & \multirow[t]{2}{*}{4,00} \\
\hline & 2 & Jlh item & 7 & 3 & 6 & 4 & 20 & \\
\hline 3 & \multicolumn{2}{|c|}{ Total skor } & 57 & 24 & 49 & 32 & \multicolumn{2}{|r|}{162} \\
\hline 4 & \multicolumn{2}{|c|}{ Mean skor } & 4,07 & 4,00 & 4,08 & 4,00 & & 4,05 \\
\hline 5 & \multicolumn{2}{|c|}{ Hasil akseptansi } & $\begin{array}{c}\text { Aksepta } \\
\text { nsi } \\
\text { tinggi }\end{array}$ & $\begin{array}{c}\text { Akseptani } \\
\text { tinggi }\end{array}$ & $\begin{array}{c}\text { Akseptansi } \\
\text { tinggi }\end{array}$ & $\begin{array}{c}\text { Akseptani } \\
\text { tinggi }\end{array}$ & \multicolumn{2}{|c|}{$\begin{array}{l}\text { Akseptansi } \\
\text { tinggi }\end{array}$} \\
\hline
\end{tabular}

Berdasarakan data hasil validasi instrumen responden yang dilakukan terhadap guru diperoleh akseptansi tinggi yaitu 4,05. Hal ini dapat diartikan bahwa e-learning menggunkana moodle berbasis e-modul dalam kategori layak untuk diterapkan di kelas XI TITL di SMKS IMELDA MEDAN.

\section{SIMPULAN}

Berdasarkan hasil penelitian yang telah di lakukan dapat di tarik kesimpulan sebagai berikut, pengembangan media e-learning menggunakan moodle berbasis e-modul di SMKS Imelda Medan berdasarkan model pengembangan ADDIE models dengan lima tahapan pokok yaitu yaitu Analysis (Analisis), Design (Desain), Develop (Pengembangan), Implement (Implementasi), dan Evaluate (Evaluasi). Hasil validasi terhadap e-learning menggunakan moodle berbasis e-modul, (a) hasil kelayakan oleh ahli materi menilai e-learning dari 2 aspek yaitu konten/materi multimedia dan kebahasaan. Berdasarkan penilaian ahli materi, kelayakan e-learning mencapai nilai rata-rata 4,00. Hal ini dapat diartikan bahwa ahli materi menyatakan e-learning berbasis e-modul pada materi instalasi penerangan listrik dalam kategori layak digunakan sebagai bahan pembelajaran, (b) hasil kelayakan oleh ahli media menilai e-learning dari 3 aspek yaitu tampilan, interaktivitas, kemanfaatan. Berdasarkan penilaian ahli media, kelayakan e-learning mencapai nilai rata-rata 4,13. Hal ini dapat diartikan bahwa 
ahli media menyatakan e-learning mengunakan moodle berbasis e-modul pada instalasi penerangan listrik dalam kategori layak digunakan sebagai bahan pembelajaran. Hasil penilaian oleh responden memberikan respon penilaian berdasarkan aspek materi multimedia, evaluasi, desain dan fasilitas media, dan efek pedagogi. Berdasarkan data hasil validasi oleh responden yang dilakukan oleh guru diperoleh akseptansi yang tinggi yaitu 4,05 dalam arti dapat diterima dengan baik.

\section{DAFTAR PUSTAKA}

Abuhassna, H., \& Yahaya, N. (2018). Students' Utilization of Distance Learning through an Interventional Online Module Based on Moore Transactional Distance Theory. EURASIA Journal of Mathematics, Science and Technology Education, 14(7). doi:10.29333/ejmste/91606

Arrahman, Alfath \& Efitayani, Cindi \& Al, Sarah. (2018). Desain E-Learning Berbasis Moodle LMS sebagai Media Pembelajaran Fluida Statis. 10.13140/RG.2.2.33314.32962.

B.SINURAT, D. I. S. (2019, December 6). Pengembangan Sistem Kurikulum Sekolah Menengah Kejuruan Untuk Menghasilkan Lulusan Yang Handal Di Indonesia. https://doi.org/10.31227/osf.io/4hdgf

Baharudin. (2018). Pengembangan Media Pembelajaran Interaktif Smk Terhadap Efektif Dan Efisiensi Pembelajaran. Jurnal Teknologi Informasi \& Komunikasi Dalam Pendidikan, 4(1). doi:10.24114/jtikp.v4i1.8749

Batubara, H. H. (2018). Pengembangan Situs e-Learning dengan Moodle versi 3.1 sebagai Media Pembelajaran pada Program Studi Pendidikan Guru Madrasah Ibtidaiyah. doi:10.31219/osf.io/tndpa

C. Asri Budiningsih. (2005). Belajar Dan Pembelajaran. Jakarta: Rineka Cipta.

Cavus, Nadire. (2015). Distance Learning and Learning Management Systems. Procedia - Social and Behavioral Sciences. 191. 872-877. 10.1016/j.sbspro.2015.04.611.

Czerkawski, B. C., \& Lyman, E. W. (2016). An Instructional Design Framework for Fostering Student Engagement in Online Learning Environments. TechTrends, 60(6), 532-539. doi:10.1007/s11528-016-0110-z

Edel, (2016). Pengertian media pembelajaran. Di akses pada 11 mei 2020 dari http://edel.staff.unja.ac.id/blog/artikel/Pengertian-Media-Pembelajaran.html

Hakim, A. R. (2018). Pengembangan E-Learning Berbasis Moodle Sebagai Media Pengelolaan Pembelajaran. Kodifikasia, 12(2), 167. doi:10.21154/kodifikasia.v12i2.1516

Hanum, N. S. (2013). Keefetifan e-learning sebagai media pembelajaran (studi evaluasi model pembelajaran e-learning SMK Telkom Sandhy Putra Purwokerto). Jurnal Pendidikan Vokasi, 3(1). doi:10.21831/jpv.v3i1.1584

Lestari, Y., Prastyawan, A., Utami, D., Noviyanti, N., \& Gamaputra, G. (2020). Pengembangan Bahan Ajar Mata Kuliah Pelayanan Publik Melalui Motode Virtual Learning. Jurnal Dimensi Pendidikan dan Pembelajaran, 8(2), 103-110. doi:http://dx.doi.org/10.24269/dpp.v8i2.2510

Marsa, A. R., \& Yunita, R. (2019). Website Media Pembelajaran Matematika Berbasis Moodle Platform. JOISIE (Journal Of Information Systems And Informatics Engineering), 3(1), 1. doi:10.35145/joisie.v3i1.332

Munir. (2009). Pembelajaran Jarak Jauh Berbasis Teknologi Informasi Dan Komunikasi. Bandung : CV Alfabeta.

Perwita, D. P., Kandika, P. S., \& oktrisma, yesni. (2019). Analisis Model Pengembangan Bahan Ajar (4d, Addie, Assure, Hannafin Dan Peck). doi:10.31227/osf.io/7bydx

Sarinah. (2015). Pengatar kurikulum. Yogyakarta: Deepublish

Sriadhi. (2019). Instrumen Penilaian Multimedia Pembelajaran.

Supratman, E., \& Purwaningtias, F. (2018). Pengembangan Media Pembelajaran E-Learning Berbasis Schoology. Jurnal Informatika: Jurnal Pengembangan IT, 3(3), 310-315. doi:10.30591/jpit.v3i3.958

Sutanta, Edhy. (2010). Konsep dan Implementasi E-Learning. Yogyakarta: IST Akprind, Jurusan Teknik Informatika, Fakultas TI

Wina sanjaya. (2012). Media Komunikasi Pembelajaran. Jakarta: Prenada Grup

Yuliana, I. (2019). Efektivitas Penerapan Blended Learning dengan Moodle sebagai Media Pembelajaran untuk Mata Pelajaran Simulasi Digital. PROtek: Jurnal Ilmiah Teknik Elektro, 6(1). doi:10.33387/protk.v6i1.998 